\title{
Staphylococci in cattle and buffaloes with mastitis in Dakahlia Governorate, Egypt
}

\author{
Maged El-Ashker, ${ }^{*}{ }^{1}$ Mayada Gwida, $† \ddagger$ Herbert Tomaso, $†$ Stefan Monecke,§\#ll Ralf Ehricht,\#II \\ Fatma El-Gohary, $\ddagger$ and Helmut Hotzel† \\ *Department of Internal Medicine and Infectious Diseases, Faculty of Veterinary Medicine, Mansoura University, Mansoura 35516, Egypt \\ †Friedrich-Loeffler-Institut, Federal Research Institute for Animal Health, Institute of Bacterial Infections and Zoonoses, Naumburger Str. 96a, \\ 07743 Jena, Germany \\ ‡Department of Hygiene and Zoonoses, Faculty of Veterinary Medicine, Mansoura University, Mansoura 35516, Egypt \\ §Institute for Medical Microbiology and Hygiene, Technische Universität Dresden, Fiedlerstr. 42, 01307 Dresden, Germany \\ \#InfectoGnostics Research Campus, 07743 Jena, Germany \\ \|Alere Technologies GmbH, Löbstedter Str. 103-105, 07749 Jena, Germany
}

\section{ABSTRACT}

The aim of this study was to provide the first detailed insight into the population structure of Staphylococcus aureus in one modern dairy farm (Gamasa) and several household cows and buffaloes in Dakahlia Governorate, Egypt. Eight hundred seventy-two quarter milk samples of 218 dairy cattle and buffaloes with clinical and subclinical mastitis were investigated. Bacteria were identified using matrix-assisted laser desorption/ionization time-of-flight mass spectrometry, and staphylococci were further characterized by DNA sequencing of $16 \mathrm{~S}$ rRNA genes and microarray analysis. Staphylococcus aureus was present in $5.6 \%$ of all collected samples, whereas methicillin-resistant $S$. aureus (MRSA) represented $24.5 \%$ of all identified $S$. aureus (12/49). Six clonal complexes (CC) of S. aureus were detected. Staphylococcus aureus CC398 (ST291/813)MSSA (methicillin-susceptible $S$. aureus) was identified frequently in the Gamasa farm in addition to a few CC5-MRSA-V isolates. However, a small number of different isolates of $S$. aureus were found in household cattle and buffaloes harboring different CC. The presence of these genotypes of $S$. aureus in milk might indicate a public health hazard, because all of these $\mathrm{CC}$ have previously been isolated from human patients. Thus, a recommendation was given to the owner of the dairy farm to review the hygiene regimen on the farm. In perspective, further investigation regarding $S$. aureus screening of all lactating cows and personnel on the farm is warranted.

Key words: bovine, mastitis, microarray, Egypt, Staphylococcus aureus CC398 (ST291/813)-MSSA

\footnotetext{
Received February 5, 2015.

Accepted July 27, 2015.

${ }^{1}$ Corresponding author: maged_elashker@yahoo.com or maged. elashker1978@gmail.com
}

\section{INTRODUCTION}

Staphylococcus aureus is a ubiquitous zoonotic pathogen of particular relevance for both human and veterinary medicine. In humans, studies have shown a prevalence of $30 \%$ in healthy carriers (van Belkum et al., 2009). Staphylococcus aureus causes a variety of skin and soft tissue infections, ranging from minor infections to life-threatening conditions such as necrotizing fasciitis, as well as pneumonia and septicemia. Some strains produce toxins, which can lead to toxic shock syndrome or food intoxication. It is estimated that intoxication caused by $S$. aureus ranks third out of common food poisoning causes, and it is associated with consumption of different categories of food including raw milk and dairy products (Headrick et al., 1998). Methicillin-resistant $S$. aureus (MRSA) strains are a major cause of nosocomial infections that lead to increased mortality rates and a substantial increase in human health care costs (Rubin et al., 1999).

In veterinary medicine, bovine mastitis is considered one of the most common and economically important diseases affecting dairy herds worldwide. It causes significant economic loss (Seegers et al., 2003). Staphylococcus aureus is one of the major pathogens causing mastitis in dairy animals (Monecke et al., 2007, Haran et al., 2012). The ability of the organism to cause a multitude of infections is probably due to the expression of various toxins, virulence factors, and cell wall adhesion proteins. The bacterium has the ability to survive phagocytosis in the udder and often causes chronic inflammation (von Eiff et al., 2006). These infections frequently do not respond to routine therapy. Hence, the economic impact of $S$. aureus mastitis is usually due to increased milk SCC, decreased milk production, increased costs of veterinary treatment, and premature culling of infected animals (Vink, 1995; Seegers et al., 2003). The resistance of $S$. aureus to antibacterial agents presents an increasing challenge and can compli- 
cate the treatment of infections (Monecke et al., 2007). High prevalence of antibiotic resistance was generally observed in both bovine and human $S$. aureus isolates from Egypt (Vink, 1995; El-Jakee et al., 2011) due to widespread, uncontrolled, and indiscriminant use of antibiotics. Thus, MRSA are continually gaining clinical significance. These strains show resistance against all types of $\beta$-lactam antibiotics that are frequently used for empirical treatment of mastitis. Fortunately, the prevalence of MRSA strains in bovine mastitis seems to be generally low (Monecke et al., 2007; Vanderhaeghen et al., 2010; Schlotter et al., 2012), but in dairy farms, the emergence of antibiotic-resistant microorganisms including staphylococci poses a potential public health hazard.

The identification and characterization of staphylococci can be performed using a multitude of phenotyping and genotyping tools such as biochemical investigations, molecular biological assays (PCR, DNA sequencing), and physical techniques such as matrixassisted laser desorption/ionization time-of-flight mass spectrometry (MALDI-TOF MS). In recent years, DNA microarrays have been developed not only to investigate the expression of multiple genes in tissues, but also to genotype bacteria and for epidemiological studies. It has recently been suggested that a variety of clonal complexes (CC) of $S$. aureus can play a role in bovine mastitis. Bovine udder infections were shown to be associated with the carriage of staphylococci that show completely different spectra of virulence factors (Herron-Olson et al., 2007; Schlotter et al., 2012). Vaccination against $S$. aureus infections would be a promising approach to prevent mastitis in dairy cattle; however, the reported efficacy of $S$. aureus vaccines remains unsatisfactory (Lee et al., 2005).

In Egypt, the population of cattle and buffaloes was 3.8 million in 2011, with buffaloes comprising $55 \%$ of the population; a total of $7,900 \mathrm{kt}$ of milk was produced (Morelon, 2011). Reliable information about the prevalence of $S$. aureus and other staphylococci among dairy cattle and buffaloes in Egypt is limited. Vink (1995) reported a mastitis prevalence of $<10 \%$ on an individual cow basis on a private farm in which $S$. aureus was the predominant pathogen $(76.2 \%$ of identified pathogens). In contrast, on a government farm that kept Holstein-Friesian cattle, the mastitis prevalence was as high as $>60 \%$ (Vink, 1995). Interestingly, buffaloes seem to be more resistant to mastitis than cows are (Vink, 1995). More recently, multidrug resistance was detected in both buffaloes and cows infected with coagulase-positive staphylococci and CNS (Dorgham et al., 2013). To our knowledge, no detailed genetic analyses are performed routinely on MRSA and methicillinsusceptible $S$. aureus (MSSA) strains isolated from
Egyptian cattle herds and household cows or buffaloes with mastitis. This study was therefore conducted to obtain detailed data on the presence of staphylococci in milk of cattle and buffaloes with clinical and subclinical mastitis in the Egyptian Nile Delta region, and to characterize $S$. aureus strains using DNA microarrays.

\section{MATERIALS AND METHODS}

\section{Animal Population}

The present study was conducted in 2011 and 2012 on 218 dairy animals (200 cattle and 18 buffaloes) with clinical $(\mathrm{n}=85)$ and subclinical mastitis $(\mathrm{n}=133)$ from different localities in Dakahlia Governorate in the eastern Nile Delta region of Egypt. Their ages ranged between 4 and 7 yr. Sixty-seven dairy cattle and 18 buffalo cows (Bubalus bubalis) were kept by smallholders at different localities at Aga district, whereas 133 dairy cattle belonged to a well-organized commercial farm located in Gamasa on the coast of the Mediterranean Sea. The Gamasa farm is located $80 \mathrm{~km}$ from the Aga district. The household cows were mostly Holstein-Friesian and only a few of them were local Egyptian breed; all dairy cattle in the Gamasa farm were HolsteinFriesian. On the farm in Gamasa, modern management techniques and good hygiene standards were applied. An automatic milking machine was used regularly at Gamasa farm.

All animals investigated were subjected to thorough clinical examination. After milking diseased animals, the size and conformation of the udder as well as the relative sizes of all quarters were inspected. The udder tissue and supramammary lymph nodes were also thoroughly examined. Animals with clinical mastitis were identified when one or more of the following signs were observed: cardinal signs of inflammation in one or more of an udder's quarters, signs of systemic reaction such as fever, depression, disturbed appetite, and abnormal physical character of milk such as clot formation, discoloration, alterations in viscosity, aberrant smell, or presence of blood. Due to the absence of observable clinical signs in animals with subclinical mastitis, the presumptive diagnosis was done based on laboratory diagnostic tests of milk samples including California Mastitis Test (CMT) and SCC. Cows with positive CMT or those having $\mathrm{SCC}>200,000$ cells $/ \mathrm{mL}$ but lacking clinical signs were considered to be affected with subclinical mastitis.

An informed consent for staphylococci investigation was given by the owners. All procedures were performed in accordance with the principles and specific guidelines presented in the Guidelines for the Care and Use of Agricultural Animals in Research and Teaching 
(3rd ed.; http://www.fass.org/), and those of Mansoura University Animal Care and approved by its Ethical Committee.

\section{Sample Collection and Primary Cultivation}

Eight hundred quarter milk samples were collected from cattle and 72 samples came from buffalo cows. Milk samples were taken aseptically and transported to the laboratory in coolers $\left(4\right.$ to $\left.8^{\circ} \mathrm{C}\right)$ for subsequent bacteriological analyses. After incubation at $37^{\circ} \mathrm{C}$ for $6 \mathrm{~h}, 100-\mu \mathrm{L}$ milk samples were plated in duplicate on sheep blood agar (Oxoid, Wesel, Germany). One plate was incubated under aerobic conditions for $24 \mathrm{~h}$ and a duplicate was incubated under anaerobic conditions for 24 to $48 \mathrm{~h}$ at $37^{\circ} \mathrm{C}$. Colonies were characterized using routine microbiological diagnostic techniques, including catalase and coagulase testing and presence of hemolysis (Koneman et al., 2005).

\section{Isolation of Staphylococcus aureus and DNA Preparation}

Colonies that were suspected to be staphylococci were subcultured on blood agar plates and Baird-Parker agar (SIFIN GmbH, Berlin, Germany) and incubated for $24 \mathrm{~h}$ at $37^{\circ} \mathrm{C}$. Genomic bacterial DNA was prepared from colonies with typical growth of staphylococci on Baird-Parker agar and subculture on blood agar, using lysis reagents from the StaphyType kit (Alere Technologies GmbH, Jena, Germany). A loop-full (1 mm in diameter) of bacteria was added to a $0.2-\mathrm{mL}$ aliquot of lysis enhancer A2 dissolved in lysis buffer A1 (both from the StaphyType kit). After incubation for $60 \mathrm{~min}$ at $37^{\circ} \mathrm{C}$ and shaking at $550 \mathrm{rpm}$ in a thermomixer, 25 $\mu \mathrm{L}$ of proteinase $\mathrm{K}$ and $200 \mu \mathrm{L}$ of buffer $\mathrm{AL}$ (both from DNeasy Blood and Tissue Kit, Qiagen, Hilden, Germany) were added. After a second incubation (30 min at $56^{\circ} \mathrm{C}, 550 \mathrm{rpm}$ in a thermomixer), the samples were processed according to the instructions of the manufacturer.

\section{MALDI-TOF MS}

Bacteria were cultured from single colonies as described above. They were suspended in $300 \mu \mathrm{L}$ of water and precipitated with $900 \mu \mathrm{L}$ of ethanol $(96 \%$ vol/vol; Carl Roth GmbH, Karlsruhe, Germany). After centrifugation for $5 \mathrm{~min}$ at $10,000 \times g$, the supernatant was removed and the pellet was resuspended in $50 \mu \mathrm{L}$ of $70 \%$ (vol/vol) formic acid (Sigma-Aldrich Chemie GmbH, Steinheim, Germany). Then, $50 \mu \mathrm{L}$ of aceto- nitrile (Carl Roth $\mathrm{GmbH}$ ) was added, mixed, and centrifuged for $5 \mathrm{~min}$ at $10,000 \times \mathrm{g}$. The supernatant was transferred into a new tube, $1.5 \mu \mathrm{L}$ of the supernatant was spotted onto an MTP 384 Target Plate Polished Steel TF (Bruker Daltonik GmbH, Bremen, Germany), and air-dried. The dried extract was overlaid with $2 \mu \mathrm{L}$ of a saturated solution of $\alpha$-cyano-4-hydroxycinnamic acid (Sigma-Aldrich Chemie $\mathrm{GmbH}$ ) in a solution of $50 \%$ acetonitrile and 2.5\% trifluoroacetic acid (SigmaAldrich Chemie $\mathrm{GmbH}$ ). Air-drying at room temperature followed. Spectra were acquired with an Ultraflex instrument (Bruker Daltonik $\mathrm{GmbH}$ ) in the linear positive mode in the range of 2,000 to $20,000 \mathrm{Da}$; acceleration voltage was $25 \mathrm{kV}$. The instrument was calibrated with the IVD Bacterial Test Standard (Bruker Daltonik GmbH). Mass spectra were acquired with 500 shots. Analysis was done with the Biotyper 3.1 software (Bruker Daltonik GmbH).

\section{Amplification, Sequencing of 16S rRNA Genes, and Data Analysis}

Bacterial isolates were identified by DNA sequencing of partially amplified $16 \mathrm{~S}$ rRNA genes. Briefly, a fragment of approximately $1,400 \mathrm{bp}$ was generated using the primer pair 16SUNI-L/R under conditions as described by Kuhnert et al. (1996). After electrophoresis on a $1 \%$ agarose gel, the bands were excised and purified using the Agarose Gel Extraction kit (Jena Bioscience GmbH, Jena, Germany) according to the instructions of the manufacturer. Cycle sequencing of the $16 \mathrm{~S}$ rRNA gene fragments was done with 16SUNI-L as sequencing primer and the BigDye Terminator v1.1 Cycle Sequencing Kit (Applied Biosystems, Darmstadt, Germany) according to the manufacturer's recommendations. Sequencing products were analyzed with a Genetic Analyzer ABI Prism 3130 (Applied Biosystems). The identification of the obtained sequences was carried out by BLAST search (http://www.ncbi.nlm.nih.gov/ blast).

\section{Microarray Analysis: Amplification, Labeling, and Array Hybridization}

The DNA microarrays of the StaphyType kit (Alere Technologies $\mathrm{GmbH}$ ) cover 333 different target sequences, which correspond to approximately 170 distinct genes and their allelic variants. Targets (e.g., species markers, resistance genes, toxin genes), protocols, data interpretation, and evaluation have been described previously (Monecke et al., 2008). Genomic target DNA was amplified in a linear manner and labeled using a multiplex primer elongation reaction incorporat- 
ing biotin-16-dUTP as described previously in detail (Monecke and Ehricht, 2005; Monecke et al., 2007). Briefly, $\sim 1 \mu \mathrm{g}$ of clonal RNA-free $S$. aureus DNA was mixed with $5 \mu \mathrm{L}$ of a master mix consisting of $4.9 \mu \mathrm{L}$ of B1 $(2 \times$ labeling buffer; Alere Technologies GmbH) and $0.1 \mu \mathrm{L}$ of B2 (DNA polymerase; Alere Technologies $\mathrm{GmbH}$ ). Amplification and labeling were carried out by using the following thermocycler protocol: 300 $\mathrm{s}$ at $96^{\circ} \mathrm{C}$ for initial denaturation was followed by 50 cycles for $60 \mathrm{~s}$ at $96^{\circ} \mathrm{C}$ for denaturation, $20 \mathrm{~s}$ at $50^{\circ} \mathrm{C}$ for annealing, $40 \mathrm{~s}$ at $72^{\circ} \mathrm{C}$ for elongation, and a final extension for $60 \mathrm{~s}$ at $72^{\circ} \mathrm{C}$. Biotinylated single-stranded amplicons were subsequently hybridized to the array followed by washing and blocking steps. Horseradish peroxidase-streptavidin conjugate was added and after further incubation and washing steps, visualization was done by precipitation with a chromogenic substrate (Alere Technologies GmbH). Finally, images of the microarray results were automatically analyzed using a designated reader and software (Alere Technologies $\mathrm{GmbH}$ ). Another recently described microarray system (Monecke et al., 2012) was used for identification of different mecA alleles of several Staphylococcus species.

\section{RESULTS}

Cattle on the farm in Gamasa were apparently healthy at the time of the study, but several cases of clinical mastitis had been recorded in previous years. In contrast, all animals owned by smallholders showed clinical signs that varied from acute inflammation in one or more quarters to complete indurations of the whole udder. On the farm in Gamasa, no detectable clinical symptoms were observed at the time of sampling although most of the collected milk samples showed variable increases in SCC. To investigate the staphylococci and other bacterial pathogens that were potentially causing these infections, 872 quarter milk samples were investigated. Briefly, 211 bacterial isolates suspected to be staphylococci (from 202 animals) were subjected to species identification using MALDI-TOF MS, DNA sequencing, and microarray analysis. Milk samples from 14 cattle with subclinical mastitis showed no growth on Baird-Parker or blood agar plates. Seven cows from the same group carried mixed infections. Two other cases had mixed cultures and no pathogen could be identified.

The results for confirmed Staphylococcus spp. isolates are given in Table 1. One hundred sixty staphylococcal isolates (18.34\% of all milk samples) were obtained. Thirty-nine originated from cattle of smallholders ( $14.55 \%$ of its milk samples) and 107 came from cattle on the Gamasa farm (20.11\%). Fourteen isolates (19.44\%) were cultured from buffalo milk of smallhold- ers. Staphylococcus aureus was detected in $3.73 \%$ of all milk samples of household cows, in $6.39 \%$ of those on the Gamasa farm, and in $8.33 \%$ of buffalo specimens. Of the obtained $S$. aureus, one isolate could not be assigned to a $\mathrm{CC}$, whereas the remaining isolates $(\mathrm{n}=$ 49) belonged to 6 different CC. Staphylococcus aureus CC398-MSSA (ST291/813) was identified frequently on the Gamasa farm as well as a few CC5-MRSA isolates. In household cows, only low numbers of $S$. aureus were found, representing 3 different CC. Twelve out of $49 \mathrm{~S}$. aureus isolates were identified as MRSA. They belonged to 3 different CC (CC5, CC22, and CC88). The detailed genetic analyses of the $S$. aureus isolates are summarized as follows.

\section{Clonal Complex 5}

Six isolates of CC5 were identified in cattle milk samples from the Gamasa farm and 3 isolates came from buffalo milk. All belonged to CC5-MRSA-V, capsule type 5 and accessory gene regulator allele ( $a g r$ group II). Isolates of this type always carry the enterotoxin gene cluster egc (seg, sei, sem, sen, seo, seu/y). The isolates were assigned to 2 separate strains based on carriage of the enterotoxin $\mathrm{D} / \mathrm{J} / \mathrm{R}$ (sed, sej, ser) genes. Isolates that harbored all 3 of these genes originated from cattle, whereas buffalo isolates were positive for enterotoxin D (sed) but negative for enterotoxin $\mathrm{I} / \mathrm{R}(\mathrm{sej} / \mathrm{ser})$. The enterotoxin A gene in the allele known from strain N315 (sea-N315 or sep; GenBank BA000018.3, position 2011380 to 2012153) was identified in the isolates obtained from buffaloes and one cow.

All CC5-MRSA-V isolates in this study carried the gene encoding an alternate penicillin-binding protein 2, defining MRSA (mecA), ugpQ (glycerophosphoryl diester phosphodiesterase), and the cassette chromosome recombinase $\mathrm{C}$ gene $(\mathrm{crC} C)$, as well as genes encoding $\beta$-lactamase (blaZ), $\beta$-lactamase repressor inhibitor (blaI), $\beta$-lactamase regulatory protein $(b l a R)$, the tetracycline resistance gene tet $(\mathrm{K})$, and the fexA gene associated with chloramphenicol resistance. Additionally, isolates from cattle harbored the tetracycline resistance tet $(\mathrm{M})$ determinant. One cattle isolate carried the macrolide/clindamycin resistance gene $\operatorname{erm}(\mathrm{B})$ and $a a c A-a p h D$, which is responsible for gentamicin and tobramycin resistance. Leucocidin genes $l u k F / S$ and $l u k D / E$ and hemolysin gamma gene $h l g A$ were detected in all isolates of this lineage. The staphylokinase gene $(s a k)$ was present in all buffalo and 2 cattle isolates. The cattle isolates also harbored scn (staphylococcal complement inhibitor gene) and one cattle isolate had the chp gene (chemotaxis-inhibiting protein) as well as the edin $B$ gene (epidermal cell differentiation inhibitor B). 
Table 1. Number of isolates of staphylococci and assignment to clonal complexes (CC) of Staphylococcus aureus isolated from milk collected from cattle and buffaloes

\begin{tabular}{|c|c|c|c|}
\hline \multirow[b]{2}{*}{ Isolate $^{1}$} & \multicolumn{3}{|c|}{ Source } \\
\hline & $\begin{array}{c}\text { Cattle } \\
\text { (smallholder) } \\
(\mathrm{n}=67)\end{array}$ & $\begin{array}{c}\text { Cattle } \\
(\text { Gamasa farm })^{2} \\
(\mathrm{n}=133)\end{array}$ & $\begin{array}{c}\text { Buffalo } \\
\text { (smallholder) } \\
(\mathrm{n}=18)\end{array}$ \\
\hline S. aureus CC5-MRSA-V & - & 6 & 3 \\
\hline S. aureus CC15-MSSA & 1 & - & - \\
\hline S. aureus CC22-MRSA-IV & - & - & 1 \\
\hline S. aureus CC88-MRSA-IV & 2 & - & - \\
\hline S. aureus CC188-MSSA & 6 & - & 1 \\
\hline S. aureus CC398 (ST291/813)-MSSA & - & 28 & 1 \\
\hline S. aureus (unknown CC) & 1 & - & - \\
\hline S. chromogenes & 7 & 16 & - \\
\hline S. cohnii & - & 2 & - \\
\hline S. epidermidis & 3 & 5 & - \\
\hline S. equorum & - & - & 1 \\
\hline S. haemolyticus & 5 & 2 & 1 \\
\hline S. hyicus & 1 & - & - \\
\hline S. pasteuri & - & 3 & - \\
\hline S. saprophyticus & 1 & 3 & - \\
\hline S. sciuri & 2 & - & - \\
\hline S. warneri & 2 & 2 & - \\
\hline S. xylosus & 8 & 40 & 6 \\
\hline Total CNS (no.) & 29 & 73 & 8 \\
\hline
\end{tabular}

${ }^{1} \mathrm{MRSA}=$ methicillin-resistant $S$. aureus; MSSA = methicillin-susceptible $S$. aureus.

${ }^{2}$ This group had 14 animals negative for staphylococcal infection and 7 animals with mixed infections.

\section{Clonal Complex 15}

One CC15-MSSA isolate was identified in a milk sample from household cattle. It was characterized by the presence of typical genomic markers as accessory gene regulator allele II (agr II alleles), capsule type 8 genes, and the $S$. aureus surface protein G gene sasG. The chemotaxis-inhibiting protein $(c h p)$ and staphylococcal complement inhibitor genes ( $s c n)$ were present but sak was absent. The $l u k F / S, l u k D / E$, and $h l g A$ genes were also detected. No enterotoxin genes were detectable. This isolate harbored blaZ, blaI, blaR, tet $(\mathrm{K})$, and the tobramycin resistance gene $a a d D$.

\section{Clonal Complex 22}

One CC22-MRSA-IV isolate from buffalo milk was identified. The buffalo isolate harbored $m e c \mathrm{~A}, \operatorname{ugp} Q$, the cassette chromosome recombinase genes A/B-2 (ccrA-2, ccrB-2), blaZ, blaI, and blRF genes, the resistance genes for macrolide/clindamycin $\operatorname{erm}(\mathrm{C})$, trimethoprim $\operatorname{dr} \mathrm{f} 1$ and $\operatorname{tet}(\mathrm{K})$. Virulence markers $l u k F, h l g \mathrm{~A}, s a k, c h p$, and scn were detected. It did not carry the ACME (arginine catabolic element) locus or Panton-Valentine leukocidin $(P V L)$. The isolate harbored the toxic shock syndrome toxin gene (tst1), and the enterotoxin gene cluster egc was present. As characteristic genomic markers of this CC, agr group I, capsule type 5, collagen-binding adhesion (cna), and the $S$. aureus surface protein G gene ( $\operatorname{sas} G)$ were found.

\section{Clonal Complex 88}

Two CC88-MRSA-IV isolates were found in milk of household cattle. They belonged to agr group III and capsule type 8 . The mecA, ugp $Q$, ccrA-2, ccrB-2, blaZ, blaI, blaR, dfrS1, and tet $(\mathrm{K})$ genes were identified. No enterotoxin genes were detected. Both isolates harbored $l u k F / S, l u k D / E, h l g A$, and the exfoliative toxin serotype A gene (etA). Furthermore, sak, chp, and scn genes were found by microarray analysis.

\section{Clonal Complex 188}

Seven isolates belonged to CC188-MSSA. Six came from milk of household cattle and one from a buffalo. These 7 isolates represented a very homogeneous group. All isolates belonged to agr group I and capsule type 8. With the exception of sea (allele as in N315), no other enterotoxin gene was identified. The isolates carried blaZ, blaI, and blaR as well as the leukocidin genes $l u k F / S, l u k D / E$, and $h l g A$. Typically for this CC, the collagen binding adhesion gene cna was present but sas $G$ and enterotoxin $\mathrm{H}(\mathrm{seh})$ were absent. The sak and $s c n$ genes were detected, whereas chp was absent.

\section{Clonal Complex 398 (ST291/813)}

Twenty-nine CC398-(ST291/813)-MSSA isolates were identified in this study: 28 came from the farm in Gamasa and 1 from a buffalo. They belonged to agr 
group I and capsule type 5. All of isolates harbored hemolysin delta $(h l d)$, etD, edinB, sak, chp, scn, and $h l g$ genes. Leukocidin genes $l u k F, l u k S$, and $l u k E$ were also present in all isolates, whereas $l u k D$ and $s a s G$ were not found. Isolates of this lineage did not yield signals for the coagulase A gene $(c o A)$; other differences to common CC398 are discussed below. Some minor differences were observed within the group of CC398 (ST291/813)-MSSA of this study. The results are given in Table 2. Although there was apparent variation in the isolates of this clonal complex, the low comparable numbers of the obtained isolates make it difficult to draw a decisive conclusion regarding the remarkable differences between cattle and buffalo. The buffalo isolate of this clonal complex showed multidrug resistance, including resistance to tetracycline, erythromycin, and clindamycin. However, the majority of cattle isolates harbored blaZ, blaI, staphylococcal enterotoxin A, and serine protease B gene.

\section{Other Staphylococci}

Table 1 also provides an overview of the identified staphylococci other than $S$. aureus. Twenty-nine isolates were cultivated from milk of household cattle and 73 originated from the Gamasa farm. Eight isolates were recovered from milk of buffaloes. The most prevalent Staphylococcus species (33.75\% of the Staphylococcus isolates) was Staphylococcus xylosus and it was found in $6.19 \%$ of all milk samples. Staphylococcus aureus (31.25 and $5.73 \%$, respectively, of staphylococci and all milk samples) and Staphylococcus chromogenes (14.37 and $2.63 \%$, respectively) were less frequent as indicated in Table 1. Other Staphylococcus species were found only sporadically. Some strains of different bacterial species harbored staphylococcal cassette chromosome mec elements (SCCmec): SCCmec IV was identified in Staphylococcus cohnii as well as in Staphylococcus epidermidis and Staphylococcus pasteuri, SCCmec II in S. epider- midis, and SCCmec V in Staphylococcus haemolyticus. A presumably unknown $S C C m e c$ element was found in Staphylococcus saprophyticus.

Besides staphylococci, other bacteria that formed dark colonies on Baird-Parker agar were identified by using MALDI-TOF MS or DNA sequencing. Sequencing of the $16 \mathrm{~S}$ rRNA gene was performed if the MALDI-TOF scores were $<2.3$. Detailed information on the identified bacterial isolates is presented in Table 3. Briefly, 51 bacterial isolates were obtained: 29 were recovered from household cows, 18 from the commercial farm, and 4 from household buffaloes. The identities of 17 isolates were determined by MALDI-TOF MS, and the remaining isolates were identified by DNA sequencing.

\section{DISCUSSION}

Milk and dairy products are an integral part of the Egyptian diet. Two different production systems coexist in Egypt: well-organized, specialized commercial farms and smallholders who keep buffaloes, cows, or both. Milk production can be affected by several bacterial pathogens that cause disease in dairy animals. Consequently, the amount of milk produced can be reduced. Mastitis, in its clinical and subclinical forms, is considered one of the most devastating diseases that affect dairy herds and represents $21 \%$ of reported diseases in dairy cattle, with an annual prevalence of 37\% (Miller and Dorn, 1990). A recently published study has shown that $3 \%$ of all animals are infected with $S$. aureus (Schukken et al., 2009). However, S. aureus represents 10 to $12 \%$ of all clinical mastitis infections (Tenhagen et al., 2009). In clinical mastitis, the abnormalities in the milk can easily be observed and the milk has to be discarded by the producer. This milk would not normally enter the food chain, whereas milk from animals with subclinical mastitis is often accidentally mixed into the bulk milk, resulting in a threat to human health. Currently,

Table 2. Characterization of variable genes of Egyptian Staphylococcus aureus clonal complex (CC)398 (ST291/813) isolates using microarray analysis

\begin{tabular}{|c|c|c|c|c|c|c|c|c|c|c|c|c|c|c|}
\hline \multirow[b]{2}{*}{ Type } & \multirow[b]{2}{*}{ Host } & \multirow[b]{2}{*}{ No. } & \multicolumn{12}{|c|}{ Gene $^{1}$} \\
\hline & & & katA & $\operatorname{co} A$ & blaZ & blaI & blaR & ermB & erm $C$ & $\operatorname{tet}(K)$ & $\operatorname{tet}(M)$ & fexA & sea & $s p l B$ \\
\hline 1 & Cattle & 41 & + & - & + & + & + & - & - & + & - & - & + & + \\
\hline 2 & Cattle & 1 & + & - & + & + & + & + & - & + & - & + & + & + \\
\hline 3 & Cattle & 4 & + & - & + & + & + & - & - & - & - & - & + & + \\
\hline 4 & Cattle & 1 & + & - & + & + & + & - & - & + & - & - & - & - \\
\hline 5 & Cattle & 1 & + & - & - & - & - & - & - & - & - & - & + & + \\
\hline 6 & Buffalo & 1 & + & - & + & + & + & + & + & - & + & - & - & + \\
\hline
\end{tabular}

${ }^{1}$ kat $A=$ katalase A gene; $c o A=$ coagulase A gene; bla $Z=\beta$-lactamase gene; bla $I=\beta$-lactamase repressor gene; bla $R=\beta$-lactamase regulatory protein gene; $\operatorname{erm} B / C=$ erythromycin/clindamycin resistance gene; tet $(\mathrm{K})$, tet $(\mathrm{M})=$ tetracycline resistance gene; fex $A=$ chloramphenicol/ florfenicol exporter gene; sea $=$ staphylococcal enterotoxin $\mathrm{A}$ gene; $s p l B=$ serine protease $\mathrm{B}$ gene. 
Table 3. Details of other nonstaphylococci bacterial isolates collected from cattle and buffalo with mastitis

\begin{tabular}{|c|c|c|c|}
\hline Isolate & $\begin{array}{c}\text { Cattle } \\
\text { (smallholder) } \\
(\mathrm{n}=67)\end{array}$ & $\begin{array}{c}\text { Cattle } \\
(\text { Gamasa farm }) \\
(\mathrm{n}=133)\end{array}$ & $\begin{array}{c}\text { Buffalo } \\
\text { (smallholder) } \\
(\mathrm{n}=18)\end{array}$ \\
\hline Enterobacter sp. & 2 & - & - \\
\hline Enterococcus faecium & 3 & 1 & - \\
\hline Enterococcus faecalis & 4 & 1 & - \\
\hline Macrococcus caseolyticus & 1 & 3 & 1 \\
\hline Enterobacteriaceae sp. & 4 & 2 & - \\
\hline Bacillus sp. & 5 & 1 & - \\
\hline Proteus sp. & 4 & - & - \\
\hline Lysinibacillus fusiformis & 1 & - & 2 \\
\hline Pseudomonas sp. & 1 & - & - \\
\hline Escherichia coli & - & - & 1 \\
\hline Kocuria sp. & 1 & 2 & - \\
\hline Corynebacterium sp. & - & 1 & - \\
\hline Enterococcus sp. & 1 & 2 & - \\
\hline Aerococcus sp. & - & 1 & - \\
\hline Vagococcus sp. & - & 1 & - \\
\hline Jeotgalicoccus sp. & - & 1 & - \\
\hline Microbacterium oxydans & - & 1 & - \\
\hline Microbacterium sp. & 1 & - & - \\
\hline Mixed culture & 1 & 1 & - \\
\hline Total (no.) & 29 & 18 & 4 \\
\hline
\end{tabular}

staphylococci are the most frequent bacterial pathogens causing bovine mastitis worldwide.

In this study, milk samples from a dairy farm in Gamasa city with 133 Holstein-Friesian cattle and those of household cattle and buffaloes were investigated with regard to the presence of staphylococci and, especially, of $S$. aureus isolates. Staphylococcus aureus was cultivated from $5.73 \%$ of all milk samples of cows and buffaloes, and MRSA strains were identified in $1.37 \%$ of all milk samples. This means that $24.5 \%$ of identified $S$. aureus were MRSA. This finding is in contrast with other investigations, where a low prevalence of MRSA (approximately 2\%) was observed among bovine isolates in Germany and Switzerland (Monecke et al., 2007; Schlotter et al., 2012) and in Korea (Lee, 2003; Moon et al., 2007).

In Egypt, a high prevalence of staphylococci strains was also observed in relation to the collected milk samples (Asfour and Darwish, 2011; Abd Al-Azeem et al., 2013; Dorgham et al., 2013; Kamal et al., 2013). The spectrum of isolates was completely different among the 3 groups regarding number of isolated bacteria and the identified CC of $S$. aureus. The number of milk samples contaminated with staphylococci on the Gamasa farm was higher than in those of the household cattle. Differences in the percentage of milk samples contaminated with staphylococci are difficult to explain. However, they could be attributed to the bias of only using one farm for the data or might be related to practices applied on this farm. All owners used concentrated feed and hay for feeding their animals. However, there were relevant differences between the farm and household animals regarding geographical distribution, population density (133 dairy cows in the farm versus $<10$ animals per smallholder herd), and the milking system. Milking was fully automated with a milking machine on the farm and was manual in case of household animals. The fact that the infections were mostly caused by the same CC suggests that one strain has spread across the herd, possibly transmitted by the milking machine. Further investigations regarding the prevalence of this type of infection among other dairy herds from different localities are highly warranted.

In general, the DNA microarray system allows the simultaneous detection of a large number of molecular targets and can facilitate a genotype-based assessment of virulence as well as of the antibiotic resistance of a given isolate. The overall hybridization profile can be used as a data set, which can help elucidate the relatedness between different isolates. The present investigation gives detailed insight into the population structure not only for MRSA but also for MSSA on one modern farm and in household cows and buffaloes in Egypt, for which few typing data are currently available. In smallholder cattle, $3 \mathrm{CC}$ were identified (CC15MSSA, CC88-MRSA, CC188-MSSA), which differed from those of the Gamasa farm, which harbored only 2 CC [CC5-MRSA and CC398 (ST291/813)-MSSA]. On the farm in Gamasa, most isolates belonged to CC398 (ST291/813). The strains recovered from buffaloes and cattle of small holders showed no epidemiological relationship among each other.

Clonal complex 5 is a common and widespread clonal complex of $S$. aureus; CC5-MRSA-V strains have been 
characterized from humans from Australia, Ireland, and Abu Dhabi (Monecke et al., 2011). Panton-Valentine leukocidin-positive CC5-MRSA-V strains have been identified in Abu Dhabi and Germany. The presence of sed but absence of sej/ser, as found in the S. aureus isolates from buffalo milk, is very unusual and warrants further characterization of the genetic environment of this toxin gene. Although CC15-MRSA are extremely rare (Monecke et al., 2011), CC15-MSSA were frequently detected in healthy humans from Europe. The described CC15-MSSA isolate is very similar to human CC15-MSSA isolates (Monecke et al., 2009) lacking enterotoxin genes and sak but carrying chp, scn, and $l u k F / S$. However, this isolate carried aadD, which is rare, at least in European isolates of this lineage.

Clonal complex 22 is a widespread clonal complex. The CC22-MRSA-IV strain from buffalo milk harbored the toxic shock syndrome toxin gene tst1, which has also been described for human isolates of this lineage from Abu Dhabi, Egypt, the United Kingdom, and United States. Thus, it is related but not identical to the widespread UK-EMRSA-15 or Barnim Epidemic Strain, which has been recovered from human patients in many countries, but also from horses, cats, and dogs (Monecke et al., 2011).

The CC88-MRSA-IV strains, which carried etA, have been identified in human patients in the Netherlands, Portugal, Angola, Senegal, and Japan (Monecke et al., 2011). The occurrence of this strain type has not yet been reported in animals. Human CC188-MSSA isolates were described in China (He et al., 2013) as well as from Trinidad and Tobago (Monecke et al., 2014). Song et al. (2015) identified this type in fresh meat and frozen food in China. The isolates recovered from milk of household cattle and one buffalo did not carry enterotoxin genes except for sea and tst1.

Here, the first observation of $S$. aureus CC398 (ST291/813)-MSSA was described from a dairy farm in Egypt. Human infections with CC398 (ST291/813)MSSA were reported in the United States (Mediavilla et al., 2012), whereas bovine isolates were found in India and Belgium (Shambat et al., 2012; Vandendriessche et al., 2014). This lineage is said to be common in Africa (Mali and Tunisia; Ruimy et al., 2008; Kechrid et al., 2011; respectively). Although CC398-MSSA is prevalent among pigs and poultry in Europe, the evolution and global dispersal of this group have yet to be clarified (Hasman et al., 2010). The ST291/813 isolate forms, as a double locus variant of ST398, a distinct lineage within CC398 (Stegger et al., 2013). Although ST291 and ST813 yielded identical hybridization patterns, they clearly differed from the "normal" CC398 such as, for example, ST398 strains. They did not yield hybridization signals for $c o A$ or $c n a$, and they differed from ST398 in alleles of ssl01 as well as genes for cell surface elastin binding protein $(e b p S)$, Ser-Asp rich fibrinogen-/bone sialoprotein-binding protein D $(s d r D)$, and type I site-specific deoxyribonuclease subunit $(h s d S)$. These genes, as well as staphylococcal protein A (spa) and acetyl-CoA acetyltransferase protein (yqil), are clustered around origin of replication (oriC), so that recombination could be a cause for the differences compared with ST398. The lack of signals for the coA gene could be attributed either to its absence or to the presence of an unknown, and undetectable, allele. Furthermore, this lineage differs from ST398 in its reactivity with $l u k E$ and serine protease $s p l$ probes. These genes are normally situated far away from oriC but close to aroE, which might indicate a second insertion/ hybridization event. Finally, they harbor et $D+e \operatorname{din} B$, but this is a potentially mobile element (Stegger et al., 2013). It seems likely that workers and veterinarians on these dairy farms are at great risk of colonization or infection. The source of the carryover of CC398 (ST291/813)-MSSA to the Gamasa farm is unclear. Possibly, milkers or other persons in the environment of this well-organized farm brought the microorganism into the herd and it was spread by close contact with the cows (e.g., contaminated milking machine, body contact). In addition, the presence of such a strain on a dairy farm would pose a public health hazard, although pasteurization of milk should ensure that this infection will not enter into the food chain.

The CNS are a group of several species that were previously considered a minor mastitis problem. Recently, CNS have been considered as important mastitis pathogens worldwide, although markers that discern colonization from infection are yet to be identified. Furthermore, many species exhibit antibacterial resistance (Lüthje and Schwarz, 2006; Björk et al., 2014; May et al., 2014) and serve as a reservoir for resistance genes as well as for SCCmec elements that can be exchanged between different species. This includes transmission to clinically more relevant $S$. aureus. The CNS have also the ability to adhere to metal equipment surfaces to produce a protective biofilm, which enables the bacteria to persist on milking equipment as well as on the milker's hands (Pilipcincova et al., 2010). In this study, the prevalence of CNS was $68.55 \%$ of all Staphylococcus isolates and $12.50 \%$ of all collected milk samples. Among the isolated CNS, Staphylococcus xylosus was isolated most frequently. This bacterium is thought to be transient in humans and can be acquired from domestic animals and their products (Bannerman, 2003). It is used by the food-processing industry as a starter culture for meat fermentation (Resch et al., 
2008). Although this bacterium is normally not associated with human infections (Otto, 2004), it has been isolated from some cases of endocarditis (Hricak et al., 1999), pyelonephritis (Tselenis-Kotsowilis et al., 1982), urinary tract infections (Orrett and Shurland, 1998), and corneal infections (Pinna et al., 1999). Additionally, some isolates of $S$. xylosus have virulence genes such as the one encoding elastase, which cleaves human IgA and IgG (Bedidi-Madani et al., 1998).

In this study, large differences between the 3 groups of animals were observed. On the farm in Gamasa, one clone of S. aureus was dominant (CC398 (ST291/813)]. Different CC were sporadically detected in other herds. It was not possible to find a relationship between the presence of $\mathrm{CC}$ or virulence factors, such as lukF$P 83 / \mathrm{M}$ of $S$. aureus isolates, and the severity of mastitis, as observed in a cattle population in Thuringia (Schlotter et al., 2012). This also indicates the presence of entirely different $S$. aureus population structures in different geographic regions, which might be relevant for future diagnostic tests or vaccine development. The low number of $S$. aureus isolates carrying enterotoxin genes (need to produce toxins and act as food-poisoning agents) is considered good news for milk producers. However, the prevalence of MRSA among the tested isolates was much higher than that reported in similar studies from Europe, warranting more investigations on livestock MRSA in Egypt. Because of this investigation, a recommendation was given to the Gamasa farm to review its hygiene regimen and cull $S$. aureus-positive animals. Further investigations of all lactating cows and the personnel on the farm are warranted.

\section{ACKNOWLEDGMENTS}

This work was funded in part by Deutscher Akademischer Austauschdienst (DAAD), Cairo, Egypt, and the Science \& Technology Development Fund, Egypt (STDF). The authors appreciate the valuable cooperation of Heinrich Neubauer, the director of FLI Jena (Jena, Germany) and for his valuable help to the first author during the stay in Germany. Special thanks are given to Rashed Hamed, veterinarian at Gamasa farm, for his fruitful help during collection of samples. We acknowledge the excellent technical assistance of Elke Müller, Annett Reißig (both of Alere Technologies, Jena, Germany), and Karola Zmuda (FLI, Jena, Germany) as well as the support by Eugen Ermantraut (formerly Alere Technologies, now BLINK GmbH in Jena, Germany). The authors thank Keri Clack (Alere Technologies) as a native speaker for the improvement of the manuscript. None of the authors of this paper has a financial or personal relationship with other people or organizations that could inappropriately influence or bias the content of the paper. Stefan Monecke and Ralf Ehricht are employees of Alere Technologies GmbH.

\section{REFERENCES}

Abd Al-Azeem, M. W., H. M. Shaheen, K. G. Abdel Hameed, and M. M. Helmy. 2013. Penicillin resistance against staphylococcal isolates recovered from subclinical mastitis in Sohag City, Egypt. Am. J. Res. Commun. 1:116-130.

Asfour, H. A. E., and S. F. Darwish. 2011. Phenotypic and genotypic detection of both mecA- and blaz- genes mediated beta lactam resistance in Staphylococcus strains isolated from mastitis. Global Veterinaria 6:39-50.

Bannerman, T. L. 2003. Staphylococcus, Micrococcus, and other catalase-positive cocci that grow aerobically. Pages 384-404 in Manual of Clinical Microbiology. 8th ed. P. R. Murray, E. J. Baron, J. H. Jorgensen, M. A. Pfaller, and R. H. Yolken. American Society for Microbiology Press, Washington, DC.

Bedidi-Madani, N., T. Greenland, and Y. Richard. 1998. Exoprotein and slime production by coagulase-negative staphylococci isolated from goats' milk. Vet. Microbiol. 59:139-145.

Björk, S., R. Båge, B. M. Kanyima, S. André, M. G. Nassuna-Musoke, D. O. Owiny, and Y. Persson. 2014. Characterization of coagulase negative staphylococci from cases of subclinical mastitis in dairy cattle in Kampala, Uganda. Ir. Vet. J. 67:12.

Dorgham, S. M., D. A. Hamza, E. A. Khairy, and R. H. Hedia. 2013. Methicillin-resistant staphylococci in mastitic animals in Egypt. Global Veterinaria 11:714-720.

El-Jakee, J. K., N. S. Atta, A. A. Samy, M. A. Bakry, E. A. Elgabry, M. M. Kandil, and W. A. Gad El-Said. 2011. Antimicrobial resistance in clinical isolates of Staphylococcus aureus from bovine and human sources in Egypt. Global Veterinaria 7:581-586.

Haran, K. P., S. M. Godden, D. Boxrud, S. Jawahir, J. B. Bender, and S. Sreevatsan. 2012. Prevalence and characterization of Staphylococcus aureus, including methicillin-resistant Staphylococcus aureus, isolated from bulk tank milk from Minnesota dairy farms. J. Clin. Microbiol. 50:688-695.

Hasman, H., A. Moodley, L. Guardabassi, M. Stegger, R. L. Skov, and F. M. Aarestrup. 2010. spa type distribution in Staphylococcus aureus originating from pigs, cattle and poultry. Vet. Microbiol. 141:326-331.

He, W., H. Chen, C. Zhao, F. Zhang, H. Li, Q. Wang, X. Wang, and H. Wang. 2013. Population structure and characterization of Staphylococcus aureus from bacteraemia at multiple hospitals in China: Association between antimicrobial resistance, toxin genes and genotypes. Int. J. Antimicrob. Agents 42:211-219.

Headrick, M. L., S. Korangy, N. H. Bean, F. J. Angulo, S. F. Altekruse, M. E. Potter, and K. C. Klontz. 1998. The epidemiology of raw milk-associated foodborne disease outbreaks reported in the United States, 1973 through 1992. Am. J. Public Health 88:1219-1221.

Herron-Olson, L., J. R. Fitzgerald, J. M. Musser, and V. Kapur. 2007. Molecular correlates of host specialization in Staphylococcus aureus. PLoS ONE 2:e1120.

Hricak, V., J. Kovacik, P. Marks, D. West, and V. Kromery. 1999. Aetiology and outcome in 53 cases of native valve staphylococcal endocarditis. Postgrad. Med. J. 75:540-543.

Kamal, R. M., M. A. Bayoumi, and S. F. A. Abd El Aal. 2013. MRSA detection in raw milk, some dairy products and hands of dairy workers in Egypt, a mini-survey. Food Contr. 33:49-53.

Kechrid, A., M. Pérez-Vázquez, H. Smaoui, D. Hariga, M. RodríguezBaños, A. Vindel, F. Baquero, R. Canton, and R. Del Campo. 2011. Molecular analysis of community-acquired methicillin-susceptible and resistant Staphylococcus aureus isolates recovered from bacteraemic and osteomyelitis infections in children from Tunisia. Clin. Microbiol. Infect. 17:1020-1026.

Koneman, E. W., S. D. Allen, W. M. Janda, P. C. Schreckenberger, and W. C. Winn Jr. 2005. Color Atlas and Textbook of Diagnostic Microbiology. 6th ed. Editora Meds, Rio de Janeiro, Brazil. 
Kuhnert, P., S. E. Capaul, J. Nicolet, and J. Frey. 1996. Phylogenetic positions of Clostridium chauvoei and Clostridium septicum based on 16S rRNA gene sequences. Int. J. Syst. Bacteriol. 46:1174-1176.

Lee, J. H. 2003. Methicillin (oxacillin)-resistant Staphylococcus aureus strains isolated from major food animals and their potential transmission to humans. Appl. Environ. Microbiol. 69:6489-6494.

Lee, J. W., C. N. O’Brien, A. J. Guidry, M. J. Paape, K. A. ShaferWeaver, and X. Zhao. 2005. Effect of a trivalent vaccine against Staphylococcus aureus mastitis lymphocyte subpopulations, antibody production, and neutrophil phagocytosis. Can. J. Vet. Res. 69:11-18.

Lüthje, P., and S. Schwarz. 2006. Antimicrobial resistance of coagulase-negative staphylococci from bovine subclinical mastitis with particular reference to macrolide-lincosamide resistance phenotypes and genotypes. J. Antimicrob. Chemother. 57:966-969.

May, L., E. Y. Klein, R. E. Rothman, and R. Laxminarayan. 2014. Trends in antibiotic resistance in coagulase-negative staphylococci in the United States, 1999 to 2012. Antimicrob. Agents Chemother. 58:1404-1409.

Mediavilla, J. R., L. Chen, A. C. Uhlemann, B. M. Hanson, M. Rosenthal, K. Stanak, B. Koll, B. C. Fries, D. Armellino, M. E. Schilling, D. Weiss, T. C. Smith, F. D. Lowy, and B. N. Kreiswirth. 2012. Methicillin-susceptible Staphylococcus aureus ST398, New York and New Jersey, USA. Emerg. Infect. Dis. 18:700-702.

Miller, G. Y., and C. R. Dorn. 1990. Costs of dairy cattle diseases to producers in Ohio. Prev. Vet. Med. 8:171-182.

Monecke, S., G. Coombs, A. C. Shore, D. C. Coleman, P. Akpaka, M. Borg, H. Chow, M. Ip, L. Jatzwauk, D. Jonas, K. Kadlec, A. Kearns, F. Laurent, F. G. O'Brien, J. Pearson, A. Ruppelt, S. Schwarz, E. Scicluna, P. Slickers, H.-L. Tan, S. Weber, and R. Ehricht. 2011. A field guide to pandemic, epidemic and sporadic clones of methicillin-resistant Staphylococcus aureus. PLoS ONE 6:e17936

Monecke, S., and R. Ehricht. 2005. Rapid genotyping of methicillin-resistant Staphylococcus aureus (MRSA) isolates using miniaturised oligonucleotide arrays. Clin. Microbiol. Infect. 11:825-833.

Monecke, S., P. Kuhnert, H. Hotzel, P. Slickers, and R. Ehricht. 2007. Microarray based study on virulence-associated genes and resistance determinants of Staphylococcus aureus isolates from cattle. Vet. Microbiol. 125:128-140.

Monecke, S., C. Lüdicke, P. Slickers, and R. Ehricht. 2009. Molecular epidemiology of Staphylococcus aureus in asymptomatic carriers. Eur. J. Clin. Microbiol. Infect. Dis. 28:1159-1165.

Monecke, S., E. Müller, S. Schwarz, H. Hotzel, and R. Ehricht. 2012. Rapid microarray-based identification of different mecA alleles in staphylococci. Antimicrob. Agents Chemother. 56:5547-5554.

Monecke, S., P. Slickers, and R. Ehricht. 2008. Assignment of Staphylococcus aureus isolates to clonal complexes based on microarray analysis and pattern recognition. FEMS Immunol. Med. Microbiol. $53: 237-251$.

Monecke, S., B. Stieber, R. Roberts, P. E. Akpaka, P. Slickers, and R. Ehricht. 2014. Population structure of Staphylococcus aureus from Trinidad \& Tobago. PLoS ONE 9:e89120.

Moon, J.-S., A.-R. Lee, H.-M. Kang, E.-S. Lee, M.-N. Kim, Y. H. Paik, Y. H. Park, Y.-S. Joo, and H. C. Koo. 2007. Phenotypic and genetic antibiogram of methicillin-resistant staphylococci isolated from bovine mastitis in Korea. J. Dairy Sci. 90:1176-1185.

Morelon, L. 2011. Dairy situation in south Mediterranean countries. Pages 18-36 in Proc. IDF World Dairy Summit, Parma, Italy.

Orrett, F. A., and S. M. Shurland. 1998. Significance of coagulasenegative staphylococci in urinary tract infections in a developing country. Conn. Med. 62:199-203.

Otto, M. 2004. Virulence factors of the coagulase-negative staphylococci. Front. Biosci. 9:841-863.

Pilipcincova, I., M. Bhide, E. Dudrikova, and M. Travnicek. 2010 Genotypic characterization of coagulase-negative staphylococci isolated from sheep milk in Slovakia. Acta Vet. Brno 79:269-275.
Pinna, A., S. Zanetti, M. Sotgiu, L. A. Sechi, G. Fadda, and F. Carta. 1999. Identification and antibiotic susceptibility of coagulase negative-staphylococci isolated in corneal/external infections. Br. J. Ophthalmol. 83:771-773.

Resch, M., V. Nagen, and C. Hertel. 2008. Antibiotic resistance in coagulase-negative staphylococci associated with food and used in starter cultures. Int. J. Food Microbiol. 127:99-104.

Rubin, R. J., C. A. Harrington, A. Poon, K. Dietrich, J. A. Greene, and A. Moiduddin. 1999. The economic impact of Staphylococcus aureus infection in New York City hospitals. Emerg. Infect. Dis. $5: 9-17$.

Ruimy, R., A. Maiga, L. Armand-Lefevre, I. Maiga, A. Diallo, A. K. Koumare, K. Ouattara, S. Soumare, K. Gaillard, J. C. Lucet, A. Andremont, and E. J. Feil. 2008. The carriage population of Staphylococcus aureus from Mali is composed of a combination of pandemic clones and the divergent Panton-Valentine leukocidinpositive genotype ST152. J. Bacteriol. 190:3962-3968.

Schlotter, K., R. Ehricht, H. Hotzel, S. Monecke, M. Pfeffer, and K. Donat. 2012. Leukocidin genes lukF-P83 and lukM are associated with Staphylococcus aureus clonal complexes 151, 479 and 133 isolated from bovine udder infections in Thuringia, Germany. Vet. Res. 43:42-49.

Schukken, Y. H., R. N. Gonzalez, L. L. Tikofsky, H. F. Schulte, C. G. Santisteban, F. L. Welcome, G. J. Bennett, M. J. Zurakowski, and R. N. Zadoks. 2009. CNS mastitis: Nothing to worry about? Vet. Microbiol. 134:9-14.

Seegers, H., C. Fourichon, and F. Beaudeau. 2003. Production effects related to mastitis and mastitis economics in dairy cattle herds. Vet. Res. 34:475-491

Shambat, S., S. Nadig, S. Prabhakara, M. Bes, J. Etienne, and G. Arakere. 2012. Clonal complexes and virulence factors of Staphylococcus aureus from several cities in India. BMC Microbiol. 12:64.

Song, M., Y. Bai, J. Xu, M. Q. Carter, C. Shi, and X. Shi. 2015. Genetic diversity and virulence potential of Staphylococcus aureus isolates from raw and processed food commodities in Shanghai. Int. J. Food Microbiol. 195:1-8.

Stegger, M., M. Aziz, T. Chroboczek, L. B. Price, T. Ronco, K. Kiil, R. L. Skov, F. Laurent, and P. S. Andersen. 2013. Genome analysis of Staphylococcus aureus ST291, a double locus variant of ST398, reveals a distinct genetic lineage. PLoS ONE 8:e63008.

Tenhagen, B. A., I. Hansen, A. Reinecke, and W. Heuwieser. 2009 Prevalence of pathogens in milk samples of dairy cows with clinical mastitis and in heifers at first parturition. J. Dairy Res. 76:179187

Tselenis-Kotsowilis, A. D., M. P. Koliomichalis, and J. T. Papavassiliou. 1982. Acute pyelonephritis caused by Staphylococcus xylosus. J. Clin. Microbiol. 16:593-594.

van Belkum, A., D. C. Melles, J. Nouwen, W. B. van Leeuwen, W. van Wamel, M. C. Vos, H. F. L. Wertheim, and H. A. Verbrugh. 2009 Co-evolutionary aspects of human colonisation and infection by Staphylococcus aureus. Infect. Genet. Evol. 9:32-47.

Vandendriessche, S., W. Vanderhaeghen, J. Larsen, R. de Mendoca, M. Hallin, P. Butaye, K. Hermans, F. Haesebrouck, and O. Denis, 2014. High genetic diversity of methicillin-susceptible Staphylococcus aureus (MSSA) from humans and animals on livestock farms and presence of SCCmec remnant DNA in MSSA CC398. J. Antimicrob. Chemother. 69:355-362.

Vanderhaeghen, W., T. Cerpentier, C. Adriaensen, J. Vicca, K. Hermans, and P. Butaye. 2010. Methicillin-resistant Staphylococcus aureus (MRSA) ST398 associated with clinical and subclinical mastitis in Belgian cows. Vet. Microbiol. 144:166-171.

Vink, D. 1995. Subclinical mastitis in the Nile Delta-A cross-sectional study. PhD thesis. Faculty of Veterinary Medicine, University of Utrecht, the Netherlands.

von Eiff, C., G. Peters, and K. Becker. 2006. The small-colony variant (SCV) concept-The role of staphylococcal SCVs in persistent infections. Injury 37(Suppl. 2):S26-S33. 